\title{
Imagine que eu sou seu sósia... Aspectos técnicos de um método em clínica da atividade
}

\author{
Matilde Batista ${ }^{\mathrm{I}}$ e Laís Rabelo ${ }^{\mathrm{II}}$

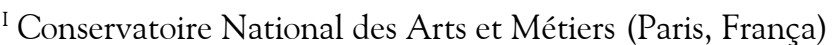 \\ ${ }^{\text {II }}$ Universidade Federal de Minas Gerais (Belo Horizonte, MG)
}

\begin{abstract}
Este artigo pretende contribuir para uma elucidação sobre alguns aspectos técnicos do método de instrução ao sósia dentro da metodologia da clínica da atividade, que busca ampliar o poder de agir dos trabalhadores. Apesar da vasta literatura sobre o tema, consideramos que há uma lacuna no que diz respeito a uma orientação mais específica sobre "como" realizar uma instrução ao sósia dentro dessa abordagem. Apresentaremos alguns elementos da aplicação da técnica que podem apoiar os profissionais que utilizam a clínica da atividade como um caminho promissor para transformar as situações degradadas de trabalho e preservar a saúde dos trabalhadores. Assim, visamos contribuir para a ampliação e a discussão dos contextos de intervenção.
\end{abstract}

Palavras-chave: Instrução ao sósia, Clínica da atividade, Trabalho, Método, Metodologia.

Imagine I'm your double... Technical aspects of a method in clinical activity

This article aims at contributing for the elucidation of some technical aspects of the method of instruction to a double under the methodology of clinical activity, which seeks to expand the worker's force. Despite the wide bibliography on the theme, we think that there is a lack of more specific guidance on "how to" conduct an instruction to a double through this approach. We will present some elements of this technique that can stimulate professionals who use the clinical activity as a promising path for changing degraded work situations and preserving the health of workers. This way, we aim to contribute to the expansion and to the discussion on intervention contexts.

Keywords: Instruction to a double, Clinical activity, Work, Method, Methodology.

\section{Origem}

Cormulado inicialmente pelo médico e psicólogo italiano Ivar Oddone, em 1970, o método Ce instrução ao sósia era utilizado em seminários de formação operária junto aos trabalhadores da FIAT, em Turim. Preocupado em recuperar e discutir a experiência concreta dos operários, ele propôs a instrução ao sósia que visava trazer à tona a forma como cada trabalhador realizava sua atividade. Tratava-se de desenvolver uma psicologia do trabalho na qual o trabalhador estivesse no papel central, pois, até aquele momento, essa disciplina prescindia de tal abordagem ${ }^{1}$. Oddone solicitava que os trabalhadores instruíssem um euauxiliar, um sósia. A demanda era formulada da seguinte maneira:

Se existisse outra pessoa perfeitamente idêntica a você, do ponto de vista físico, como você diria a ela para se comportar na fábrica, em relação à tarefa, aos colegas, à hierarquia e à organização informal, de forma que ninguém percebesse que não se trata de você mesmo? (Oddone, Re \& Briante, 1981, p. 57, tradução livre).

\footnotetext{
1 Inclusive podemos nos perguntar se, atualmente, os avanços propostos por Oddone são levados a termo ou se continuamos a nos pautar em uma psicologia que pretende observar de fora o que se passa na realidade de trabalho.
} 


\section{A apropriação da instrução ao sósia pela clínica da atividade}

Com a mesma preocupação de Ivar Oddone, o psicólogo francês Yves Clot recuperou, posteriormente, o método de instrução ao sósia. Reinventou o método dentro da teoria, dos objetivos e da metodologia da clínica da atividade, que busca transformar as situações laborais degradadas por meio da coanálise da atividade de trabalho. Baseado na concepção vygotskyana de que o "homem é pleno a cada minuto de possibilidades não realizadas" (Vygotsky, 1925/1994, p. 41, citado por Clot, 2007, p. 115), a clínica da atividade vai além da clássica proposta da ergonomia francesa acerca da distância entre o trabalho prescrito e o trabalho real (Daniellou, Laville \& Teigeir, 1989) ao acrescentar o real da atividade, conceito que diz respeito ao:

[...] que não se faz. O que se tenta fazer sem ser bem sucedido - o drama dos fracassos - o que se desejaria ou poderia ter feito e o que se pensa ser capaz de fazer noutro lugar [...] o que se faz para evitar fazer o que deve ser feito; o que deve ser refeito, assim como o que se tinha feito a contragosto (Clot, 2010, p. 104).

Para a clínica da atividade, a transição, de dupla-via, entre o real da atividade e a atividade realizada é fonte de desenvolvimento para os sujeitos ${ }^{2}$. Entretanto, o real da atividade não é observável e acessível diretamente, sendo necessário um método indireto que permita aos sujeitos transformar a experiência vivida de um objeto em um objeto de uma nova experiência vivida.

Contudo, aceder ao real da atividade não significa descartar a atividade realizada, mas se servir dela para alcançar a atividade não observável. Pois é justamente nas diferentes realizações da experiência que o real da atividade pode se duplicar. A transformação da experiência vivida em meio de fazer uma nova experiência torna manifesto o real da atividade nos seus desenvolvimentos. Isso porque entre o real da atividade e a atividade realizada existe uma contradição que oferece uma possibilidade quando o primeiro se realiza. Neste processo, o real pode se reorganizar e se modificar. $\mathrm{O}$ sujeito se produz neste vir a ser do real na atividade realizada e vice-versa (Clot, 2001). A tomada de consciência não se define pelo resgate de um passado intacto, mas na recriação da experiência passada que é revivida na ação presente. Esse é o princípio norteador de uma metodologia histórica e desenvolvimental praticada na clínica da atividade.

Vale destacar a diferença entre a metodologia e o método em clínica da atividade. A metodologia da clínica da atividade busca criar as condições necessárias para que os trabalhadores sejam capazes de transformar seu ofício, aumentando assim seu poder de agir. Para tanto, um dos momentos da intervenção consiste na realização de métodos como a instrução ao sósia e/ou das autoconfrontações simples ou cruzadas que buscam favorecer o acesso dos trabalhadores ao real da atividade. Muitas vezes, verifica-se uma confusão entre método e metodologia, ou, ainda, o equívoco de que a intervenção em clínica da atividade se resume à aplicação dos métodos.

As instruções ao sósia e as autoconfrontações se limitam a técnicas, mas, dentro da metodologia da clínica da atividade, podem provocar uma transformação do trabalho, pois possibilitam o deslocamento das atividades para outros contextos e, consequentemente, para diferentes destinatários.

A redefinição do método da instrução ao sósia, na forma como foi apropriada pela clínica da atividade, pressupõe o entendimento de que os trabalhadores, os próprios, são os efetivos transformadores de seu trabalho. Sendo assim, o psicólogo tem um papel preciso: criar

2 Para um melhor entendimento da relação entre real da atividade e atividade realizada, ver o capítulo 2 da terceira parte de Clot (2010). 
as condições necessárias para o processo de análise da atividade pelos trabalhadores, recusando o lugar de expert na análise do trabalho. O principal objetivo do clínico da atividade é atingido quando os trabalhadores se utilizam dele como meio para seu desenvolvimento. Nesse sentido, a intervenção com a instrução ao sósia, ao resgatar a história do desenvolvimento real do sujeito, possibilita dar visibilidade aos obstáculos e às possibilidades insuspeitas na situação de trabalho (Clot, 2010) e, assim, oferece condições para que os trabalhadores cuidem do seu próprio ofício.

\section{Alguns aspectos relevantes na condução de uma instrução ao sósia}

Consideramos que, apesar da ampla publicação em clínica da atividade em torno do tema ${ }^{3}$, há uma lacuna, no contexto brasileiro, no que diz respeito a uma orientação mais específica sobre "como" realizar uma instrução ao sósia dentro da abordagem téoricometodológica da clínica da atividade. Apresentaremos, então, alguns aspectos técnicos da condução do método que podem apoiar os profissionais que veem na clínica da atividade um caminho promissor para transformar as situações degradadas de trabalho e preservar a saúde dos trabalhadores.

É importante dizer que este artigo não expõe uma experiência brasileira de utilização do método de instrução ao sósia. O objetivo é contribuir para a prática da clínica da atividade ao colocar em foco as características do método que são constantemente demandadas às autoras por terem formação ${ }^{4}$ e experiência com a metodologia da clínica da atividade.

Acreditamos que as técnicas de condução da intervenção nesta abordagem são de suma importância, por permitirem uma ação mais precisa do clínico da atividade tendo em vista os objetivos a serem alcançados. Contudo, essas formas de fazer não devem ser tomadas como a única possibilidade de uso do método. Se as descrevemos aqui é com o intuito de que por meio delas possamos discutir seus efeitos e contribuir no desenvolvimento das maneiras de intervir. Mas, quando não sabemos como agir, o desenvolvimento dos métodos indiretos podem se constituir como imensos obstáculos na realização da intervenção. Além disso, é indispensável esclarecer que nossa proposta não é uma fórmula de como fazer instruções ao sósia, mas uma orientação que deve, frente às dificuldades colocadas pelas realidades concretas de trabalho, ser reinventada e transformada.

Ainda destacamos que a utilização do método é passível de outros fins que não envolvem necessariamente os objetivos dessa orientação teórico-metodológica, como, por exemplo, o uso para uma coleta de dados. Entretanto, quando deslocada dos pressupostos da clínica da atividade, a simples aplicação do método pode não promover o desenvolvimento do trabalho, além de mobilizar afetos importantes que podem colocar o sujeito em situação vulnerável, sem o espaço necessário para elaborar transformações no seu ofício. A técnica de instrução ao sósia em clínica da atividade tem como momento primordial a ação, ou seja, a intervenção nas situações degradadas de trabalho, não se restringindo à produção de conhecimento acadêmico sobre determinado ofício. Isso não significa que a produção de conhecimento seja menos importante que a intervenção, mas que o conhecimento deve ser produzido a partir dos resultados da ação.

Em função dos objetivos deste artigo e dos limites da discussão, partiremos do pressuposto de que os outros momentos metodológicos da intervenção em clínica da atividade

3 Para mais esclarecimentos sobre os aspectos teórico-metodológicos da clínica da atividade, ver: Clot (2007, 2010).

4 No Conservatoire National des Arts et Métiers (França) há um curso de especialização em instrução ao sósia; o mesmo não se verifica no Brasil. 
já foram realizados. Assim, supõe-se que a comanda/demanda já foi apresentada, discutida e enquadrada dentro da proposta de intervenção; um grupo de pares já esteja constituído, ou seja, trabalhadores que realizam a mesma atividade e se apresentam como voluntários para a participação subsequente; os encontros já foram negociados etc. Passemos, então, para o desenrolar do método a partir de tópicos que julgamos importantes no sentido de auxiliar a condução do processo.

\section{Explicitação das regras ao grupo}

Parte importante do processo reside na discussão, com trabalhadores voluntários, acerca das regras que devem ser seguidas no desenvolvimento da intervenção. São essas regras que vão enquadrar os participantes a um contexto específico que lhes permita pensar o trabalho.

Antes de iniciar as instruções, os participantes devem estar cientes de que não há resposta certa ou errada, pois o intuito é avançar na análise das diferentes maneiras de realizar a atividade de trabalho. A discussão das diferentes formas de agir que cada trabalhador realizará na atividade dialógica é possibilidade de alimentar a discussão. Também é importante ressaltar que todo o processo se dá dentro do coletivo de trabalho, ou seja, na presença de um grupo de pares.

\section{A regra central}

A instrução ao sósia pressupõe que clínico da atividade deverá ser o sósia de um trabalhador e o substituirá em sua atividade de trabalho. O sósia é "um interlocutor deliberadamente artificial que apresenta um defeito irremediável: não sabe, mas deve saber" (Clot, 2007, p. 149). O clínico da atividade instaura a seguinte norma ao trabalhador: "Suponha que eu seja seu sósia e que amanhã vou substituí-lo em seu local de trabalho. Quais instruções você deveria me transmitir para que ninguém perceba a substituição?" (Clot, 2007, p.144).

Diante dessa proposta, o trabalhador deve colocar-se na posição de instrutor e, dessa forma, ajudar seu sósia "a se orientar em uma situação que ele não conhece, ao lhe indicar não só o que faz habitualmente, mas também aquilo que não faz nessa situação, aquilo que deveria, sobretudo, não fazer ao substituí-lo, aquilo que ele poderia fazer, mas que não se faz etc." (Clot, 2007, p. 146).

\section{A sequência de trabalho}

Delimitar uma sequência de trabalho facilita a focalização da experiência nos detalhes da execução da atividade (Clot, 2007). A escolha da sequência pode ser definida pelo trabalhador que será o instrutor ou também pode ser objeto de debate no grupo de pares. Contudo, deve conter uma atividade real, com a qual o trabalhador já esteja habituado. Para facilitar a suposta substituição do trabalhador pelo sósia, é importante que se construa uma projeção para um futuro próximo e concreto, com dia e hora marcados (exemplo: Instrutor Você me substituirá amanhã, no turno da tarde, na atividade da recepção).

\section{A instrução}

Nessa troca dialógica, o trabalhador deve, de fato, assumir sua posição de instrutor. Para tanto, é interessante que suas falas sejam realizadas na segunda ou terceira pessoa do singular, como se o sósia já estivesse em seu lugar, ou seja, o instrutor deve se referir à sua 
atividade usando o "tu" ou "você", e não o pronome "eu". O sósia pode ajudar que essa regra se mantenha, lembrando ao instrutor quem exercerá as atividades (exemplo: Instrutor - Aí eu chego perto da mesa. Sósia - Então eu chego perto da mesa? Instrutor - Sim, você chega perto da mesa e pega os papéis). Também é importante que o sósia não tome decisões diante de duas ou mais possibilidades colocadas pelo instrutor (exemplo: Instrutor - Você pode subir com a escada ou com um banquinho. Sósia - Eu vou fazer como você faz. Devo subir com a escada ou com um banquinho?). O sósia deve recolocar os lugares para forçar o deslocamento do sujeito, podendo, assim, ver sua atividade de uma nova perspectiva.

Segundo Clot (2010), "nenhuma reflexão direta sobre a ação é possível de si para si" (p. 201), vindo daí a importância de propor ao trabalhador que descreva sua própria atividade levando em conta seu interlocutor, o sósia:

A análise das relações entre o sujeito e sua própria atividade - objeto do trabalho de instrução - é dirigida para a atividade do sósia que incide sobre esse objeto. [...] Essa situação em que o sujeito dialoga consigo mesmo sob a restrição com o outro torna sua experiência "alheia" (Clot, 2007, p. 144).

$\mathrm{Ou}$, nos termos de Vygotsky, esse exercício torna-se "um contato social consigo mesmo" (Vygotsky, 1925/1994, pp. 46-47, citado por Clot, 2007, p. 144).

\section{As intervenções do sósia}

O sósia deve impedir o fluxo linear da descrição da atividade, já que ele não vê a atividade como o próprio instrutor a vê. O sósia deve descobrir a atividade. Assim, ele interrompe o discurso do instrutor em todos os momentos em que ocorre uma descrição lacunar de uma sequência, quando não compreende bem o que deve fazer, quando percebe que há outras possibilidades de fazer ou, ainda, de não fazer etc. Nesse sentido, "o sósia, ao buscar sem jamais encontrar - todos os possíveis e todos os obstáculos da situação que não conhece [...] substitui o sujeito antes das escolhas que ele fez, nas contradições em que este se vê e nas quais encontrou [...]" (Clot, 2007, p. 147). Logo, o clínico da atividade enquanto sósia "multiplica os obstáculos a fim de aprender mesmo aquilo que o outro não previu lhe ensinar" (Clot, 2007, p. 149). Nesse movimento, o sósia deve levar em consideração as quatro dimensões propostas originalmente por Oddone, Re e Briante (1981), quais sejam: a relação do trabalhador com sua própria tarefa, com os colegas, com a hierarquia e com a organização informal.

Assim, mais que um receptor de instruções, o sósia será também um questionador que, nesse momento, se detém ao como fazer e não ao por que o sujeito realiza a atividade da forma como a realiza. Pois, se o sósia deve substituir o instrutor, ele buscará fazer como o instrutor faz, e não saber por quais motivos deve fazê-lo (exemplo: Instrutor - Aí, você organiza as ferramentas. Sósia - Organizo como?). Com isso, instaura-se uma troca discursiva que será recuperada como objeto de elaboração em um momento subsequente. Essa situação dialógica deve ser orientada de forma que o sósia faça o trabalhador revelar os subentendidos e os implícitos que sua atividade comporta. O resultado dessa fase é, sobretudo, a descrição das escolhas feitas pelo sujeito na realização de sua atividade (Scheller, 2001).

\section{Logo após a instrução...}

A instrução tem duração de cerca de uma hora. Depois da instrução terminada, o clínico abandona a posição de sósia e pergunta ao trabalhador: "O que esse exercício provocou/causou em você?". Essa pergunta possibilita uma reflexão acerca dos efeitos da experiência sobre o sujeito, principalmente porque não é raro que os instrutores sejam 
fortemente afetados pelo exercício. Assim, falar sobre o que a instrução provocou no sujeito é uma estratégia clínica para que o ele se refaça.

Após a explanação do trabalhador, o clínico da atividade dá a palavra aos demais membros do grupo, presentes como observadores, que, a partir de então, podem ocupar o lugar do sósia (exemplo: Trabalhador-sósia - Se um paciente me pedir, eu posso entregar os exames nos horários que não estão previstos?). Este momento deve ser conduzido pelo clínico da atividade de forma que os colegas prossigam o trabalho do sósia. Os pares devem tentar ajudar o instrutor na análise de sua atividade por meio de questionamentos que visem esclarecimentos sobre os pontos não compreendidos ou sobre as formas de realizar a atividade que não foram detalhadas. Dessa maneira, qualquer tentativa de sugestão ou de orientação de como o trabalho deve, ou não deve, ser feito precisa ser impedida pelo clínico da atividade, levando os colegas a buscar compreender a atividade do instrutor, mas não devem, de maneira alguma, avaliá-la. Até este ponto, o que ocorre é uma autoconfrontação, ou seja, o sujeito é confrontado consigo mesmo pela mediação do(s) sósia(s) frente ao coletivo de pares.

Em seguida, o trabalhador receberá a gravação de áudio integral da instrução e deverá, posteriormente, escutá-la, transcrevê-la ${ }^{5}$ e elaborar um comentário para ser apresentado nos próximos encontros do grupo. Nesse momento, o clínico da atividade pode indicar passagens às quais considera que o trabalhador deva voltar sua atenção, tais como: silêncios, risos, bloqueios, irritações, surpresas etc.

A partir dos traços materializados da instrução, o sujeito desenvolve uma atividade de escrita que não é mais dirigida ao sósia, mas ao grupo de análise. O retorno ao exercício de instrução pelo trabalhador, por meio da escuta, da transcrição, das reflexões e dos comentários, proporciona uma retomada da própria atividade de trabalho, que inclui as possibilidades realizadas e aquelas não realizadas, ou seja, a gênese das escolhas, compreendida pelos comportamentos que venceram e aqueles que foram abandonados, mas não abolidos.

\section{Próximos passos e encontros}

Após a realização dos passos anteriores, o grupo continuará a se encontrar dentro de um intervalo a ser definido, tendo em vista o tempo necessário de reflexão por parte do trabalhador acerca da sua instrução, mas também a disponibilidade de encontro de todos os membros do grupo. Assim são possíveis intervenções em que as sessões se desenrolam uma vez por mês, ou a cada quinze ou vinte dias, ou mesmo semanalmente. Essas sessões em grupo são variadas: podem ser realizadas durante um dia inteiro, com os intervalos necessários; durante dois dias consecutivos a cada dois meses; uma vez por semana, durante duas ou três horas etc. A definição da frequência dos encontros tem efeitos importantes, embora não possam ser pensados independentemente de outros aspectos da condução do processo.

É interessante que o próximo encontro seja iniciado com a retomada da última instrução realizada, ou das últimas, caso mais de um trabalhador tenha realizado o exercício. Ou seja, antes da próxima instrução, o clínico da atividade deve abrir espaço ao trabalhador (ex-instrutor) perguntando-lhe como foi ouvir a própria gravação, o que encontrou de significativo e quais foram os comentários que produziu em torno desses momentos. Essa fase permite que o trabalhador compartilhe algumas de suas reflexões, assim como possíveis elaborações suscitadas pela instrução e pela análise posterior. Nesse momento, as análises

5 Considerando que o ato de transcrever cerca de uma hora de gravação, em geral, implica mais de cinco horas de trabalho, tempo de que os trabalhadores geralmente não dispõem, sugerimos a transcrição parcial - escolha de passagens da instrução - como uma possibilidade de aplicação do método. Estamos conscientes das mudanças substanciais que esse tipo de configuração acarreta no decorrer da intervenção, embora não estejamos convencidas de que esse formato impeça a elaboração dos trabalhadores e comprometa os desenvolvimentos que podem dela decorrer. Sendo assim, optamos por utilizar o dispositivo e compreender as implicações de fazê-lo desta maneira. 
voltam-se para o grupo e buscam destrinchar as razões pelas quais o profissional realiza sua atividade de uma maneira específica. Assim, passa-se de "como" para o "por que" se faz.

Após a finalização das instruções, os próximos encontros serão destinados a uma reflexão coletiva em torno das diferentes formas de fazer o trabalho que vieram à tona. Ressaltamos que tal reflexão não se dará necessariamente apenas neste momento de conclusão, pois não há linearidade no processo de análise da atividade de trabalho.

\section{Considerações finais}

A riqueza do método, para os fins apresentados no início deste artigo, reside no fato de que as atividades não se mantêm fixas, congeladas. Elas se desenvolvem, graças ao fato de que as verbalizações, nesse contexto, não servem de expressão às atividades prontas. No processo de transformação das atividades em linguagem, elas se reorganizam e se modificam. A linguagem realiza a atividade no sentido pleno do termo:

Com o sósia, o sujeito introduz-se em diálogos exteriores e interiores. Eles podem ser considerados como exercícios estilísticos que lhe permitem tomar consciência do que faz nesse exato momento ou do que se desfaz para, eventualmente, voltar a fazê-lo. [...] A análise do trabalho se revela como um instrumento de desenvolvimento da consciência do sujeito quando lhe é oferecida a possibilidade de alterar o estatuto do vivido: de objeto de análise, o vivido pode tornar-se meio para viver outras vidas (Clot, 2010, p. 223).

Assim, o que se busca na clínica da atividade é ampliar o raio de ação do trabalhador pela modificação do estatuto do vivido, que o sujeito tome em suas mãos sua própria história para se propor um novo futuro (Clot, 2010).

Nesse sentido, acreditamos que devemos, assim como fazemos junto aos trabalhadores, desenvolver os meios para cuidar do nosso próprio ofício. É evidente que uma breve explicitação de aspectos ligados às técnicas do método de instrução ao sósia não poderá sanar todas as lacunas e os obstáculos para uma intervenção em clínica da atividade, pois essa é apenas uma parte daquilo que é necessário para desenvolver nosso trabalho. Contudo, as discussões a respeito das formas de realizá-lo, pela exposição das técnicas desenvolvidas para atingir os objetivos, podem diminuir os impedimentos para fazer a intervenção. Isso não significa que a intervenção em clínica da atividade esteja livre dos impedimentos que podem frustrá-la. Mas é justamente colocando em debate as formas de intervir que poderemos analisar os limites e as possibilidades para fazer delas instrumentos de transformação de nosso próprio ofício. E, claro, esse percurso não se faz sozinho. Conscientes, então, do esforço que devemos realizar para tomar em nossas mãos nossa própria história e da necessidade da construção de um coletivo que possa impulsionar tal desenvolvimento, esperamos ter contribuído com alguns modestos elementos para o debate.

\section{Referências}

Clot, Y. (2001). Méthodologie en clinique de l'activité. L'exemple du sosie. In M. Santiago-Delefosse \& G. Rouan (Eds.), Les méthodes qualitatives en psychologie (pp. 125-147). Paris: Dunod.

Clot, Y. (2006). Vygotsky: para além da psicologia cognitiva. Pro-posições, 17 (2), 19-30.

Clot, Y. (2007). A função psicológica do trabalho (2ª ed.). Petrópolis: Vozes. 
Clot, Y. (2010). Trabalho e poder de agir. Belo Horizonte: Fabrefactum.

Daniellou, F., Laville, A. \& Teiger, C. (1989). Ficção e realidade do trabalho operário. Revista Brasileira de Saúde Ocupacional, 17 (68), 7-13.

Oddone, I., Re, A. \& Briante, G. (1981). Redécouvrir l'expérience ouvrière: vers une autre psychologie du travail? Paris: Messidor.

Scheller, L. (2001). L'élaboration de l'expérience du travail. La méthode des instructions au sosie dans le cadre d'une formation universitaire. Education Permanente, 146, 161-174.

\section{Endereço para correspondência}

matildeagero@yahoo.com.br, laisdibella@gmail.com

Recebido em: 25/08/2011

Revisado em: 05/11/2012

Aprovado em: 08/11/2012 